\title{
Bioengineering, University, Government, and Industry: A Visit to a Small College
}

\author{
James V. Masi, \\ Western New England College, Dept. of Electrical Engineering, Springfield, MA 01119
}

\begin{abstract}
The Program in bioengineering offers a unique opportunity to integrate the fields of physics and bioengineering into a coherent learning experience which helps the student learn engineering and physics by helping the physically challenged. Through cooperative programs with Shriners Hospital, Baystate Medical (.Tufts), Monsanto Chemical Co., and (for certain devices) NASA Technology Utilization, students from Western New England College, School of Engineering enter into design experiences which have as their goal the solution (via bioengineering and biophysics) of problems unique to the handicapped individuals.

The experience related in this paper is that of an engineering professor's teaching involvement in this merger of physics, bioengineering, industry, government, and student/patient in one of the most rewarding experiences the author has observed in over thirty years of his career. This experience is from the perspective of some of the problems and advantages of a small college.

This paper shares these experiences, the advantages, the problems, and the tally of positives and negatives of ten years of this unique teaching/learning experience. Typical industry, classroom, and hospital situations are described with their attendant reactions from teacher, patient, student, and industry. Implementation strategies are suggested for those who wish to develop such a program. Future scenarios for improvement are also discussed.
\end{abstract}

\section{INTRODUCTION}

The need for better devices for the physically and mentally challenged has existed for many years. The development of such devices has been delayed and often halted by the cost, lack of standards, lack of return on investment, and individual tailoring necessary for usefulness to the task at hand. Though rehabilitation and bioengineering institutions such as N. I. D. R. R., R. E. S. N. A., bit, etc. have served to help to fill the void and develop a fine array of devices for the handicapped, a more broad-based approach touching, not only the handicapped, but the students, institutions, hospitals, and government must be set in place to set aside, by way of educational goals, the barriers which often fail to close the loop. In addition, usual funding sources earmarked for schools with larger numbers of faculty and accredited programs are not accessible to small colleges whose bioengineering program is not accredited, due to size alone. It is in this setting that the Program in Bioengineering at Western New England College in 1982 set up, as part of its Capstone Course, called Senior Design Projects, a cooperative utilizing the facilities of the school, industry, and hospital, the talents of professor, medical professional, industrial technologist, and student, and the base of ideas generated by all parties, including NASA's Technology Utilization Services (as found in NASA Tech Briefs). The meetings of the parties involved, student, professor, medical professional, industrial advisor, and patient, was part of the structure which proceeded quite easily. The orchestration of the effort was the only portion of the program remaining to be clarified. How would costs be shared? How would time be allocated? Who would own the invention if one resulted from the work? How does a SMALL school keep this going in the light of declining funding and increasing legal implications?

\section{STRUCTURE OF THE COURSE}

- The students, in the beginning of their junior (third) year of studies, are introduced to a course called Practicum in Bioengineering. The rationale for this course stems from the need for students in engineering, especially bioengineering, to learn their engineering in the real world with the design of devices and software which serve the needs of handicapped individuals. At

$$
\text { 等 }
$$


this time, in this course, the students take on, through a hospital and/or bioengineering related industry or institution, the design of a material, an enabling device, improvement of an existing device, or analysis of a present method, materiaJ, or design. This course, complete with progress reports, fabrication and/or analysis, and final report and design, serves as a stepping stone to the capstone senior design project which the student elects as either a one semester, three credit, or a two semester, six credit design course, culminating in the design, fabrication, and demonstration of the device/material. A fully edited, critiqued, and three stage approved fipal report is written as well as orally presented to an audience of peers, professors, industrial advisors, medical personnel, and, most importantly, the patient.

The committee for the project is made up of the student, the professor, the patient, the doctor or medical personnel, and/or the industrial advisor. NASA requests that, upon approval of the final report, they have the permission to reprint selected portions in their annual magazine called SPINOFF. The professor, having already met with the institution, patient, and institutional personnel, decides first as to the appropriateness of the design task(s). The student and professor next meet to determine if the project is suited to the student. This is followed by the student's acceptance, in writing, of the project as described. Next step is the meeting, for clarification and specificity, of the professor, student, and medical personnel. If industrial sponsorship is involved, the industrial advisor also enters into this meeting. Either at this meeting or the next, the patient is introduced to the team (who should, by this time, have their act together). At this time everyone finally hears "what the customer (patient) ordered. Hopefully, this coincides with what has been discussed in the previous meetings.

The grade for the course is given as a composite of the committee's evaluation, with the student as a non-voting member, of course. Any potential patent rights are usually foregone in hopes that the resultant device or material is produced in the open marketplace, with benefit given to the participating hospital, industry, and the patient. In the case of new materials with other applications and/or new devices with applications outside of the enabling functions, agreements are reached with all parties involved. Many times, employment in the participating industry will result for the capstone project student. In short, everyone gains from the experience.

PARTICIPATING INDUSTRIES, GOVERNMENT AGENCIES, AND HOSPITALS

A tabular cross-section of some of the hospitals, industries, and government organizations involved in the design project are given below.

\title{
Table 1
}

\section{Tabular Summary of Supporting Institutions}

\section{Industries/Government}

Monsanto Chemical Corp

Johnson and Johnson

Berkshire Industries

United Technologies Corp.(5 divisions)

Bristol Myers-Squibb (two divisions)

DuPont Chemical (three divisions)

General Electric (two divisions)

Naval Undersea Weapons Center (Composites)

Kema Nobel Companies

\section{Hospitals/Institutes}

Shriners Hospital for Crippled Children

Baystate Medical Systems (Tufts West)

Newington Children's Hospital

San Diego Children's Hospital
Galileo Electro Optics Co.

Digital Equipment Corp.

Pertec Corp.

Genzyme Corp.

Pfizer Corp.

Beckman Industries (Medical)

Mobay Plastics

Dover Systems/Intergraph

\section{PROJECTS AND DEVICES DEVELOPED}

Range

The range of topical area coverage is broad. They cover such areas as materials for new prosthetic devices, gait analysis and device development, low-cost computer aided speech devices, minimally invasive vascular compliance measurement devices, adaptive toys, upper and lower limb prosthetics, low cost elbow and knee prostheses, myoelctric hands and elbows, interns!l prosthetics, and functional electrical stimulation devices and measurements.

\author{
Mass. General Hospital \\ Mercy Hospital \\ Diabetes Association \\ Institute for the Blind, Institute for the Deaf
}




\title{
Sampling of Projects
}

Three of the many devices and projects are described (following) as typical of the level and complexity of capstone design projects.

\section{Eccentric Knee Prosthesis}

Two of the major problems associated with prosthetic knee joints are the fact that these joints are expensive (in excess of $\$ 700$ for a fourbar linkage) and the toddler sizes are not yet perfected for a small child. The appearance of a offset mechanism for a robotic arm for satellite retrieval in a NASA TECH BRIEF, May, 1988 looked as though the mechanism was simple enough to provide the "feel" and range of motion similar to an anatomical knee. Shriners Hospital, Springfield, MA was contacted, a patient was identified, a student was assigned, and NASA was contacted for further information. Monsanto, Indian Orchard, MA was asked to help with the selection of polymers to make the knee lightweight, strong, self-lubricative, and lower cost than its cast aluminum, fourbar counterpart. The design shown in Figure 1 shows a comparison between (a) the existing fourbar version and (b) the offset, polymeric version designed. The final result was a knee which emulated the action of the anatomical knee better than its fourbar counterpart, cost under $\$ 30$ in parts (\$85 to manufacture), was $29 \%$ of the weight of the fourbar knee, and had the added benefit of being useful for patients who wanted to swim (no parts to corrode). Patients were fitted and are now users. A study of growth and adaptive refitting is underway.
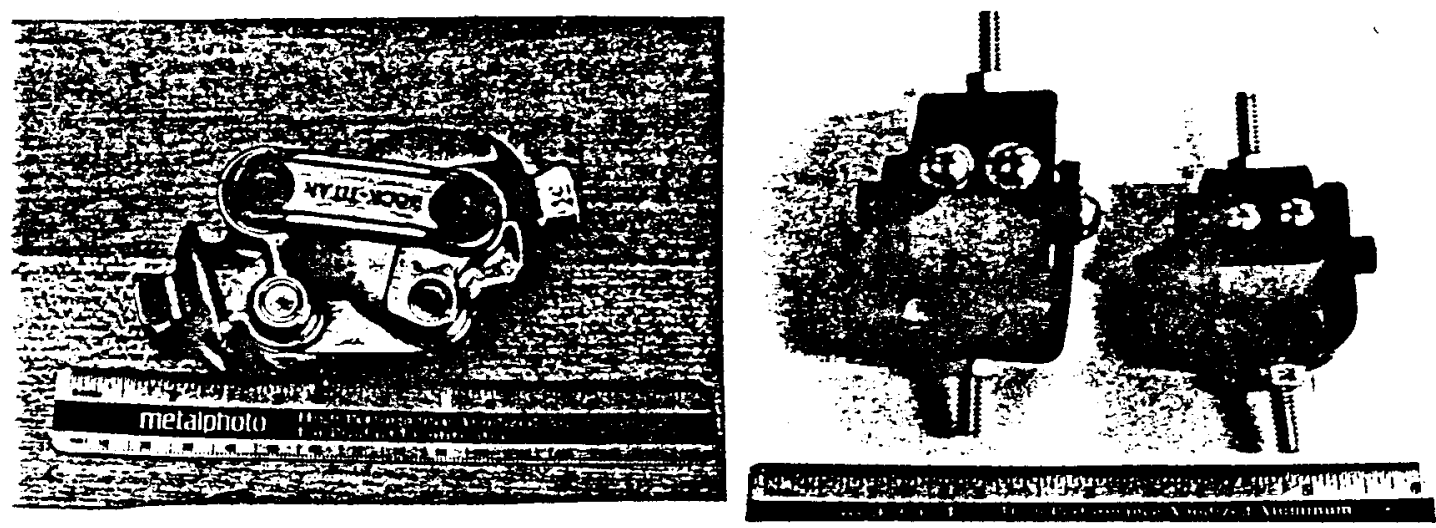

(a) Old Fourbar version

\author{
(b) New Polymeric offset version . \\ Figure 1 \\ Prosthetic Knees
}

\section{Prosthetic Knees}

The student and patients enjoyed the receipt of applause and intense questioning from the staff of the Shriners Hospital, after their presentation and demonstration of the knees. A similar presentation, in addition to the senior capstone design presentation, was made by the student to the freshman class, which received it enthusiastically, at an introductory class called "The Freshman Experience".

\section{Active Ventilated Prosthesis for Below the Knee Amputees}

Heat removal from lower residual limbs has been a problem in the fabrication of prosthetic devices, and passive devices have been marginally successful. Lingering moisture and odor present a formidable task to overcome in the dynamic environment associated with the region of the residual limb. Newington Children's Hospital and Shriners Hospital identified a recent trauma case patient who was 15 years old, au atMete (basketball), and a below the knee amputee. A student' was invited to participate in the overall rehabilitation problem and design an active cooling/sensing/moisture-removal system for a ventilated socket. The industrial sponsor, ELINA Motors, provided sponsorship for the cooling portion. Shriners and Newington Hospital provided prosthetic fabrication facilities and personnel. The design yielded a lightweight, low-noise, low cost, low power consumption

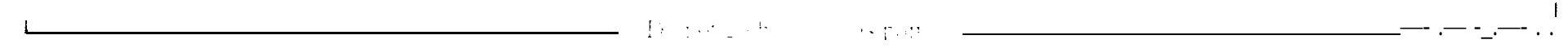


system using standard, off-the-shelf components. The device is shown below with fan, circuit, battery, socket, sensors separated for viewing. The ribbed construction on the walls of the socket provided, with the active cooling and moisture removal, a four degree Celsius drop in temperature on the patient during strenuous sports activity. The cost of the assembly was under $\$ 200$, including labor. At present, five patients (a laborer, two students, one bilateral amputee, and an athlete/student are wearing these devices, These components and socket are shown below in Figure 2
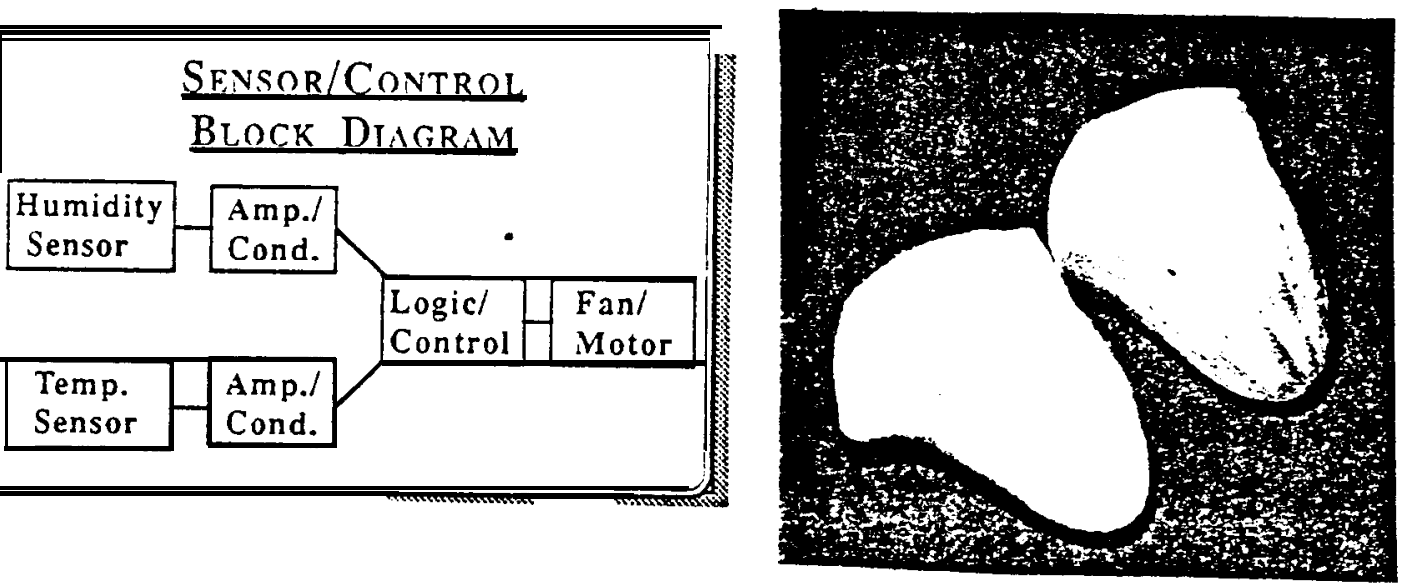

Figure 2

Active Ventilated Prosthesis

The junior bioengineering class visited Shriners Hospital and witnessed a joint presentation involving the student, the patient, the doctor,, and the professor. The building and testing of the monitoring electronics and the printed circuit board design and fabrication became the topic of one of the junior labs in the following semester.

\section{Arterial Bypass Outflow Resistance Monitor (Pre-Treatment Vascular Compliance)}

The methods associated with the testing of arteries prior to operations or to test vascular elasticity are often as traumatic as the procedure to follow, especially to an already physically or mentally challenged patient. Baystate Medical (.Tufts West), Springfield, MA had a need to test venous and arterial sections prior to procedures, operative and therapeutic. This system should monitor the pressures accumulated in the vessel when a known amount of fluid was injected into the vein or artery. The performance of the vein or artery could be determined from a measurement known as arterial/vascular resistance. From these measurements, the physician could make decisions such as quality of artery for bypass, stenosis level, sclerosis level, etc. Students" who had an interest in going into cardiac medicine were identified and agreed upon. IBM Donated an XT Computer for the task. NASA offered their search facilities to help in background identification processes. Over the two year period, various phases of the task were accomplished, culminating in hardware, software, device, and accuracy validation and a system shown in Figure 3 below. The system has become the method used by surgeons at BayState Medical for vascular compliance. Two companies are bidding on rights to manufacture this system, benefits going to the Hospital and School

-The attendant classroom situation involved the student's presentation to his peers, not only in the capstone course, but in the biomechanics course in the section regarding cardiovascular mechanics. The student also made a presentation to an assembly of interns and residents at Baystate Medical Center, evoking "some of the best discussion I have seen in years", according to the medical professor in charge of the class and the project.

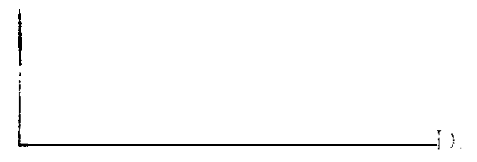




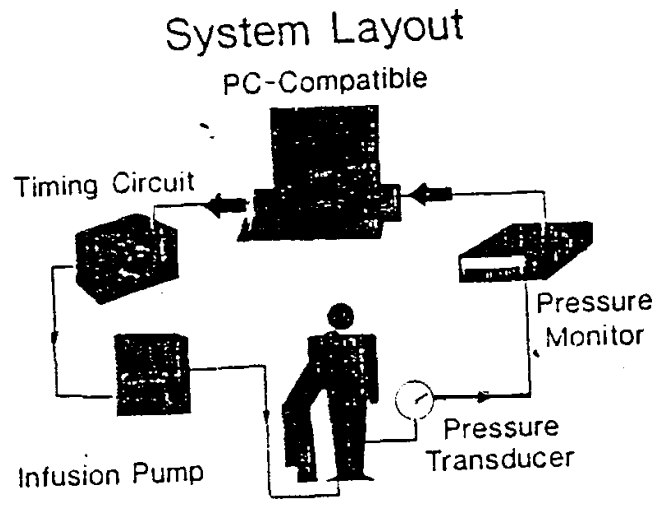

(a) System Layout .

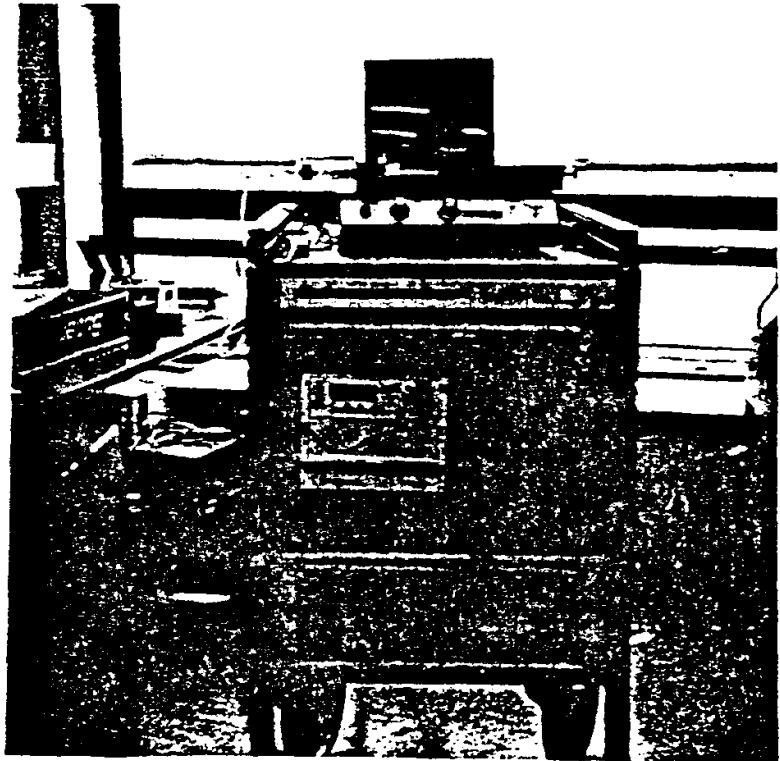

(b) System on H.P. Cart

Figure 3

\section{RESULTS AND CONCLUSIONS}

Vascular Compliance Measurement System

The Program in Bioengineering at Western New England College in accordance with their Capstone Senior Project have been " serving the needs of the physically and mentally challenged for over 12 years. In cooperation with hospitals, industries, and the government, useful and enabling devices have been developed and used with a high level of success and lower than normal development costs. It has been a highly positive experience for all involved. The win-win scenario for all involved has made this mode of capstone course delivery very popular in the school, the hospitals, and the community at large. The talley of positives and negatives comes out very much on the positive side, as shown above. On the negative side, problems associated with the implementation have been largely bureaucratic and litigious in nature. Insurance questions, publicity and publication rights, and patent/manufacturing issues have arisen, but only rarely, considering the number of projects over the years. Funding and equipment was less of a problem than anticipated. All parties and the community pull together to help the handicapped. The personal interface of student and patient and the metamorphoses resulting in attitudes, friendships, and overall learning add to the credibility of the statement that "People, not things, make both engineering and the engineer what they are."

ENDNOTES

1. IEEE TRANSACTIONS ON REHABILITATION ENGINEERING, Volume 1, No. 1, March, 1993. pp. 1-3. This charter issue' is devoted to a description of the field and the problems associated with rehabilitation engineering.

2. NOTE: The word committee always should be followed by its implied definition: "A camel is a racehorse designed by committee."

3. Derouin, F., "A Prosthetic Lightweight Knee with Improved Function and Lower Cost for Children", Senior Capstone Design, Bioengineering, Western New England College, Springfield,MA01119. June, 1993.

4. Nelson, T., "Ventilated Socket and Active Prosthetic Device", Senior Capstone Design, Bioengineering, Western New England College, Springfield, MA 01119. June, 1990.

5. Daley, J. and Trottier, T., "Development of an Arterial Bypass Outflow Resistance Monitor", Senior Capstone Design, Bioengineering, Western New England College, Springfield,MAO1119. June, 1989 and 1991 respectively. 